\title{
Editorial
}

Journal of

Molecular Microbiology

\section{Psychobiotics and Their Involvement in Mental Health}

\author{
Fengyi Tang ${ }^{a}$ Bhaskara L. Reddy ${ }^{a, b}$ Milton H. Saier Jr. ${ }^{a}$ \\ ${ }^{a}$ Department of Molecular Biology, Division of Biological Sciences, University of California at San Diego, La Jolla, \\ Calif., and ${ }^{\mathrm{b}}$ Department of Mathematics and Natural Sciences, College of Letters and Sciences, National University, \\ Ontario, Calif., USA
}

Ingested prebiotic organic compounds stimulate the growth of intestinal probiotic bacteria [Saier and Mansour, 2005]. Pre- and probiotics represent important components in chains of complex biosynthetic and catabolic reactions that provide tremendous health benefits to the human or animal host organism [Singh et al., 2013; Vitetta et al., 2014]. These bacteria, which in part comprise the intestinal microbiome, do so by supplying nutrients such as short-chain fatty acids [Ohashi and Ushida, 2009] and precursors of enzyme cofactors including vitamin $\mathrm{B}_{12}$ [Capozzi et al., 2012]. They also successfully compete with potential pathogens [Corr et al., 2009] and stimulate host immune responses [Jirillo et al., 2012; Vitaliti et al., 2014]. They strongly influence either positively or negatively, depending on the bacterial types present, symptoms of numerous metabolic disorders including those responsible, in part, for the current obesity epidemic [Kotzampassi et al., 2014; Vitetta et al., 2014]. Therefore, not surprisingly, malnutrition in children has been shown to be associated with a lack of certain crucial gut bacteria [Subramanian et al., 2014]. It is now clear that the intestinal microbiome influences innumerable processes essential for the physical fitness of animals and humans.

\section{KARGER}

(c) 2014 S. Karger AG, Basel

1464-1801/14/0244-0211\$39.50/0

E-Mail karger@karger.com

www.karger.com/mmb
The contribution of beneficial gut bacteria to human health is now scientifically well established [Shanahan et al., 2012]. The predominant well-studied probiotic bacteria are Firmicutes such as Lactobacillus species, Actinobacteria such as Bifidobacterium species and Bacteroidetes such as Bacteroides species. Several others, including Proteobacteria such as certain Escherichia coli strains, have also been shown to exhibit probiotic qualities. In fact, all of these microbes have beneficial consequences to the host organism. In only a few cases have the probiotic bacterial mechanisms of action been elucidated [Butel, 2014].

Since these bacteria influence so many aspects of human physiology, it should not be considered surprising that recent studies have revealed that they also have pronounced effects on brain function. Indeed, these bacteria produce tryptophan, a precursor of serotonin (5-hydroxytryptamine), tyrosine, a precursor of L-3,4-dihydroxyphenylalanine (DOPA) and dopamine, and other amino acids such as $\gamma$-amino butyric acid (GABA) and glycine, both of which serve as neurotransmitters in animals [Clarke et al., 2014b]. In fact, recent research has shown that the microbiota strongly influences brain activity and consequently behavior. It exerts effects on our moods, cognition and sensitivities to pain [Borre et al., 
2014a]. While most of the mechanisms involved are still poorly defined, the molecular details of relevant processes are beginning to be understood.

For example, Bifidobacterium breve, in a strain-specific fashion, influences the compositions of brain fatty acids and lipids [Wall et al., 2012], altering and responding to changes in fatty acid metabolic rates [Barrett et al., 2012a]. Changes in phospholipid membrane compositions can alter neuronal sensitivities and neurotransmission in well-understood processes [Altrup et al., 2006].

Because of the emergence of 'mind-altering' probiotics relevant to psychiatry, a new term 'psychobiotics' has been coined to describe this exciting emerging field [Dinan et al., 2013]. A psychobiotic is defined as 'a live organism that, when ingested in adequate amounts, produces health benefits in patients suffering from a psychiatric illness' [Dinan et al., 2013]. The importance of bidirectional channels of communication between the brain and our microbiota is only now beginning to be realized. However, it is significant to note that these tiny microbes have been implicated in stress-related psychological disorders such as anxiety, autism and depression [Borre et al., 2014a; Dinan and Cryan, 2013]. In fact, it is already established that the gut microbiota, acquired during infancy, has an impact on the central nervous system and behavior from childhood on into adult life [Clarke et al., 2014a].

During fetal and early childhood development, probiotic organisms such as bifidobacteria and lactobacilli maintain a healthy balance between pro- and anti-inflammatory responses during their primary colonization stages [Vitaliti et al., 2014]. They play essential roles in the neuroimmune and neuroendocrine development of the host [Saulnier et al., 2013]. Microbially derived peptides and neuroactive mediators of neurotransmission (e.g. GABA, catecholamines and acetylcholine) induce synthesis and release of molecules by gut epithelial cells that modulate neural signaling [Bailey, 2014]. For example, while Escherichia and Streptococcus probiotic strains produce norepinephrine and serotonin, Bifidobacterium and Lactobacillus species release GABA and acetylcholine [Barrett et al., 2012b]. Different classes of nerve and immune cells express quantitatively different receptors for neurotransmitters [Lang and Bastian, 2007; Pannell et al., 2014 ], and consequently they respond differently to these compounds.

Neurotrophic factors produced by the gut microbiota trigger an immunogenic reaction in the infant, producing a mixture of local and systemic responses. Norepinephrine, for example, produces sympathetic proinflamma- tory effects at low-to-moderate systemic levels [Spengler et al., 1990], which in the presence of bacterial lipopolysaccharide, stimulate leukocytes to produce adrenocorticotropic hormone (corticotropin), a local peptide stress hormone [Harbour-McMenamin et al., 1985]. On the other hand, acetylcholine, produced by many probiotic bacteria, decreases proinflammatory cytokine release [Borovikova et al., 2000]. Bifidobacteria and lactobacilli lack bacterial lipopolysaccharide and adrenergic factors, thus decreasing the proinflammatory response during colonization. Changes in neuroplasticity can also occur depending on glial cell responses to GABA and serotonergic neurotransmitters [Pannell et al., 2014].

The gut microbiota has been shown to raise the levels of serotonin and serotonergic precursors in newborn mice during gut colonization [Clarke et al., 2013]. Aside from their psychological effects, these compounds depress indoleamine-pyrrole 2,3-dioxygenase, a proinflammatory enzyme, moderating hypothalamic-pituitaryadrenal production of cortisone and cortisone-related factors [Clarke et al., 2013]. The balance of pro-/anti-inflammatory pathways and the serotonergic regulatory mechanism operate synergistically, affecting appetite, sleep and mood, and modulating cortisol and cortisolderivative release [Christmas et al., 2011]. Thus, the gut microbiota is likely to play a fundamental role in the interplay of neural, immune and hypothalamic-pituitaryadrenal development in young people [Dinan and Cryan, 2012].

It is not surprising that disruption of the human infant microbiota may lead to severe consequences. For example, extensive use of antibiotics has been shown to disrupt the microbial community in healthy infants, leading to microbial imbalance or dysbiosis. Alterations of the gut microbiota, especially in the formative years, have been implicated in altered brain development and plasticity. This can lead to changes in motor function and social behavior [Clarke et al., 2013; Diaz Heijtz et al., 2011; Sudo et al., 2004]. Moreover, breast-fed infants have a completely different microbial population than formula-fed babies with consequent health benefits that can last a lifetime [Goehring et al., 2014; Le Huerou-Luron et al., 2010].

The human animal is born with a surprisingly poorly developed nervous system compared to other mammals, including other primates. Very few $(<10 \%)$ of the axonal nerve connections are established at birth relative to the human adult [Churchland and Sejnowski, 1988; Suhler and Churchland, 2011; Churchland, pers. commun.]. This serves as both a disadvantage (the human baby is far more altricial, being totally dependent on its mother) and 
an advantage (it has a greater capacity to learn after birth during extensive neural development) [Churchland and Sejnowski, 1988]. It should not be surprising that development of the human microbiota occurs parallel to brain development and that the two normally develop in a mutually beneficial, cooperative fashion. Consequently, early-life perturbations in gut microbiota impact neurodevelopment, leading to the emergence of adverse mental health problems years later [Borre et al., 2014b].

The concept of parallel evolution, with complex microbial-neural interactions and interdependencies, opens up new therapeutic preventative approaches in early life to combat childhood and adult mental illnesses. Naturalistic medicine seeks to develop nutritional strategies to foster strong probiotic environments in patients, while the biotechnology industry investigates potential prebiotic drugs for practical applications [Dinan et al., 2013]. A detailed understanding of the evolutionary and physiological importance of the host-microbial system as a coevolved ecosystem with interdependencies typical of complex, long-standing, multiorganismal systems must be emphasized. In this regard, it should be recalled that the adult human body contains roughly 10 times the number of bacterial cells as human cells [Macfarlane and Macfarlane, 1997]. The ecological, metabolic, physiological and psychological interrelationships are only now becoming fully recognized. This fertile field of study is ripe for further investigation.

\section{References}

- Altrup U, Hader M, Caceres JL, Malcharek S, Meyer M, Galla HJ: Epileptogenic drugs in a model nervous system: electrophysiological effects and incorporation into a phospholipid layer. Brain Res 2006;1122:65-77.

Bailey MT: Influence of stressor-induced nervous system activation on the intestinal microbiota and the importance for immunomodulation. Adv Exp Med Biol 2014;817:255-276.

- Barrett E, Fitzgerald P, Dinan TG, Cryan JF, Ross RP, Quigley EM, Shanahan F, Kiely B, Fitzgerald GF, O'Toole PW, Stanton C: Bifidobacterium breve with alpha-linolenic acid and linoleic acid alters fatty acid metabolism in the maternal separation model of irritable bowel syndrome. PLoS One 2012a;7:e48159.

- Barrett E, Ross RP, O’Toole PW, Fitzgerald GF, Stanton C: Gamma-aminobutyric acid production by culturable bacteria from the human intestine. J Appl Microbiol 2012b;113: 411-417.

Borovikova LV, Ivanova S, Zhang M, Yang H, Botchkina GI, Watkins LR, Wang H, Abumrad N, Eaton JW, Tracey KJ: Vagus nerve stimulation attenuates the systemic inflammatory response to endotoxin. Nature 2000; 405:458-462.

Borre YE, Moloney RD, Clarke G, Dinan TG, Cryan JF: The impact of microbiota on brain and behavior: mechanisms \& therapeutic potential. Adv Exp Med Biol 2014a;817:373403.

- Borre YE, O’Keeffe GW, Clarke G, Stanton C, Dinan TG, Cryan JF: Microbiota and neurodevelopmental windows: implications for brain disorders. Trends Mol Med 2014b, Epub ahead of print.

Butel MJ: Probiotics, gut microbiota and health. Med Mal Infect 2014;44:1-8.

Capozzi V, Russo P, Duenas MT, Lopez P, Spano
G: Lactic acid bacteria producing B-group vi-
tamins: a great potential for functional cereals
products. Appl Microbiol Biotechnol 2012;
96:1383-1394.

Christmas DM, Potokar J, Davies SJ: A biological pathway linking inflammation and depression: activation of indoleamine 2,3-dioxygenase. Neuropsychiatr Dis Treat 2011;7:431439.

Churchland PS, Sejnowski TJ: Perspectives on cognitive neuroscience. Science 1988;242: 741-745.

Clarke G, Grenham S, Scully P, Fitzgerald P, Moloney RD, Shanahan F, Dinan TG, Cryan JF: The microbiome-gut-brain axis during early life regulates the hippocampal serotonergic system in a sex-dependent manner. Mol Psychiatry 2013;18:666-673.

Clarke G, O’Mahony S, Dinan T, Cryan J: Priming for health: gut microbiota acquired in early life regulates physiology, brain and behaviour. Acta Paediatr 2014a;103:812-819.

-Clarke G, Stilling RM, Kennedy PJ, Stanton C, Cryan JF, Dinan TG: Mini-review: gut microbiota: the neglected endocrine organ. Mol Endocrinol 2014b:28:1221-1238.

Corr SC, Hill C, Gahan CG: Understanding the mechanisms by which probiotics inhibit gastrointestinal pathogens. Adv Food Nutr Res 2009;56:1-15.

- Diaz Heijtz R, Wang S, Anuar F, Qian Y, Bjorkholm B, Samuelsson A, Hibberd ML, Forssberg H, Pettersson S: Normal gut microbiota modulates brain development and behavior. Proc Natl Acad Sci USA 2011;108:3047-3052.

Dinan TG, Cryan JF: Regulation of the stress response by the gut microbiota: implications for psychoneuroendocrinology. Psychoneuroendocrinology 2012;37:1369-1378.
Dinan TG, Cryan JF: Melancholic microbes: a link between gut microbiota and depression? Neurogastroenterol Motil 2013;25:713-719.

Dinan TG, Stanton C, Cryan JF: Psychobiotics: a novel class of psychotropic. Biol Psychiatry 2013;74:720-726.

Goehring KC, Kennedy AD, Prieto PA, Buck RH: Direct evidence for the presence of human milk oligosaccharides in the circulation of breastfed infants. PLoS One 2014;9:e101692.

-Harbour-McMenamin D, Smith EM, Blalock JE: Bacterial lipopolysaccharide induction of leukocyte-derived corticotropin and endorphins. Infect Immun 1985;48:813-817.

Jirillo E, Jirillo F, Magrone T: Healthy effects exerted by prebiotics, probiotics, and symbiotics with special reference to their impact on the immune system. Int J Vitam Nutr Res 2012;82:200-208.

Kotzampassi K, Giamarellos-Bourboulis EJ, Stavrou G: Obesity as a consequence of gut bacteria and diet interactions. ISRN Obes 2014; 2014:651895.

Lang K, Bastian P: Neurotransmitter effects on tumor cells and leukocytes. Prog Exp Tumor Res 2007;39:99-121.

Le Huerou-Luron I, Blat S, Boudry G: Breast- v. formula-feeding: impacts on the digestive tract and immediate and long-term health effects. Nutr Res Rev 2010;23:23-36.

Macfarlane GT, Macfarlane S: Human colonic microbiota: ecology, physiology and metabolic potential of intestinal bacteria. Scand J Gastroenterol Suppl 1997;222:3-9.

Ohashi Y, Ushida K: Health-beneficial effects of probiotics: its mode of action. Anim Sci J 2009;80:361-371. 
Pannell M, Szulzewsky F, Matyash V, Wolf SA, Kettenmann H: The subpopulation of microglia sensitive to neurotransmitters/neurohormones is modulated by stimulation with LPS, interferon-gamma, and IL-4. Glia 2014; 62:667-679.

-Saier MH Jr, Mansour NM: Probiotics and prebiotics in human health. J Mol Microbiol Biotechnol 2005;10:22-25.

Saulnier DM, Ringel Y, Heyman MB, Foster JA, Bercik P, Shulman RJ, Versalovic J, Verdu EF, Dinan TG, Hecht G, Guarner F: The intestinal microbiome, probiotics and prebiotics in neurogastroenterology. Gut Microbes 2013;4: $17-27$.

-Shanahan F, Dinan TG, Ross P, Hill C: Probiotics in transition. Clin Gastroenterol Hepatol 2012;10:1220-1224.

-Singh VP, Sharma J, Babu S, Rizwanulla, Singla A: Role of probiotics in health and disease: a review. J Pak Med Assoc 2013;63:253-257.
Spengler RN, Allen RM, Remick DG, Strieter RM, Kunkel SL: Stimulation of alpha-adrenergic receptor augments the production of macrophage-derived tumor necrosis factor. J Immunol 1990;145:1430-1434.

Subramanian S, Huq S, Yatsunenko T, Haque R, Mahfuz M, Alam MA, Benezra A, DeStefano J, Meier MF, Muegge BD, Barratt MJ, VanArendonk LG, Zhang Q, Province MA, Petri WA Jr, Ahmed T, Gordon JI: Persistent gut microbiota immaturity in malnourished Bangladeshi children. Nature 2014;510:417-421.

Sudo N, Chida Y, Aiba Y, Sonoda J, Oyama N, Yu XN, Kubo C, Koga Y: Postnatal microbial colonization programs the hypothalamic-pituitary-adrenal system for stress response in mice. J Physiol 2004;558:263-275.
Suhler CL, Churchland P: Can innate, modular 'foundations' explain morality? Challenges for Haidt's moral foundations theory. J Cogn Neurosci 2011;23:2103-2116; discussion 2117-2122.

Vitaliti G, Pavone P, Guglielmo F, Spataro G, Falsaperla R: The immunomodulatory effect of probiotics beyond atopy: an update. J Asthma 2014;51:320-332.

Vitetta L, Briskey D, Alford H, Hall S, Coulson S: Probiotics, prebiotics and the gastrointestinal tract in health and disease. Inflammopharmacology 2014;22:135-154.

Wall R, Marques TM, O'Sullivan O, Ross RP, Shanahan F, Quigley EM, Dinan TG, Kiely B, Fitzgerald GF, Cotter PD, Fouhy F, Stanton C: Contrasting effects of Bifidobacterium breve NCIMB 702258 and Bifidobacterium breve DPC 6330 on the composition of murine brain fatty acids and gut microbiota. Am J Clin Nutr 2012;95:1278-1287. 